Hydrology and Earth System Sciences, 6(5), 819-831 (2002) C C EGS

\title{
The mineralogy and chemistry of fine-grained sediments, Morphou Bay, Cyprus
}

\author{
Colin Neal \\ Centre for Ecology and Hydrology, Crowmarsh Gifford, Wallingford, Oxon, OX10 8BB, UK
}

Email: cn@ceh.ac.uk

\begin{abstract}
The mineralogy and chemistry of the less than $20 \mu \mathrm{m}$ fraction of marine sediments at Morphou Bay, north-west Cyprus, are presented to characterise fine-grained sediment supplies from basic and ultrabasic rocks of the Troodos Massif within a typological setting. The sediments comprise a mixture of smectite, illite, kaolinite and iron rich chlorite. They also contain amorphous iron oxides/hydroxides, calcite (with some magnesium substitution for calcium) and an amphibole. Spatial patterns in mineralogy occur: the near-shore sediments are rich in smectite, chlorite, amphibole and amorphous iron oxides/hydroxides, while the offshore sediments are rich in illite and calcite. The sediments are calcium, magnesium, iron, aluminium and potassium bearing, due to the presence of significant amounts of calcite (for Ca), clay minerals and aluminium and iron oxides/hydroxides. Potassium is present within the micaceous mineral illite, but it is also contained within other phases that are difficult to pinpoint. Statistical analysis reveals that the chemical composition of the sediments broadly follows the mineralogy with the dominant feature being related to spatial changes in the mineralogy. The patterns of change reflect a three component mix of claysized sediment types: (1) localised lithogenous sources rich in smectite with subsidiary amounts of amorphous iron oxides/hydroxides and amphibole, from Cyprus, the Troodos in particular, (2) illite rich and smectite chlorite and chlorite bearing material of lithogenous origin from other parts of the eastern Mediterranean and (3) calcite, mainly of marine origin.
\end{abstract}

Keywords: smectite, illite, chlorite, kaolinite, calcite, sediments, Morphou Bay, Troodos, Cyprus, Mediterranean, calcium, potassium, magnesium, iron, silicon, phosphorus.

\section{Introduction}

Over the last decade, much greater awareness of the importance and vulnerability of the World's coastal zone ecosystems has provided an impetus for national and international research to examine the interaction of landbased chemical and sediment fluxes to estuaries, the continental shelf and the open sea. The new initiatives include the Land Ocean Interaction Study (LOIS) for eastern UK rivers entering the North Sea, the European Land Ocean Interaction Study (ELOISE) and the Land Ocean Interaction in the Coastal Zone programme (LOICZ) at the global level (Leeks and Jarvie, 1998). All these initiatives are linked to the International Geosphere Biosphere Programme (IGBP) that deals with describing and understanding the interactive physical, chemical and biological processes that regulate the total earth system (IGBP, 1994).

Within these programmes, there is an emerging 'typological' theme of characterising different types of coastal environment in order to describe the key physical, chemical and biological interactions (Crossland et al., 1999). Such information is required for scaling up to simulate, via GIS approaches, the regional and global environment.

In this paper, the mineralogy and chemistry of fine-grained sediments in Morphou Bay, Cyprus is presented to represent a coastal zone whose sediments are derived from ophiolite (oceanic crust and mantle derived rocks of basic and ultrabasic character) and which are relatively unpolluted from local land-based sources. The fine-grained sediments were focussed on since minerals and amorphous phases present in this fraction have a disordered structure and high surface area, which induce high chemical reactivity (Drever, 1997). The ophiolite area of Cyprus provides a major centre for geological and hydrochemical research (Neal and Shand, 2002): it is an environment of particular value as an environmental endmember case within the context of typological settings. 


\section{Study area}

Morphou Bay, lying to the north-west of Cyprus in the eastern Mediterranean (Fig. 1), is bounded to the south by the northern edge of the Troodos Massif and to the east by the western limits of the Mesaoria Plain and the Kyrenia range: the west and north of the bay is open water.

With respect to geomorphology and geology, the Troodos Massif, the Mesaoria Plain and the Kyrenia range differ (Wilson and Ingham, 1984; Gass and Masson-Smith, 1963; Gass, 1982; Lippard, 1986; Neal and Shand, 2002). The Troodos Massif comprises a large proportion of the mid- to south-eastern side of Cyprus, a flattened oval, elongate in an east-west plane. The range is between 25 and $35 \mathrm{~km}$ wide with a maximum altitude of about 1940 m.a.s.l. It is composed of a full ophiolite sequence, the deeper plutonic ultrabasic core cropping out in the centre of the massif. Partly surrounding the ophiolite massif are foothills of Cretaceous to Miocene age chalks. The Mesaoria Plain, between the Kyrenia and Troodos ranges, has bedrock composed of
Pliocene, Pleistocene and recent sediments (marls, fluvial sands, fanglomerates, alluvium and clays, etc.) and the elevation typically is less than 300 m.a.s.l. The Kyrenia range is about $90 \mathrm{~km}$ long in an east-west direction and narrow in a north-south direction (typically $5 \mathrm{~km}$ across) with a height of up to about 910 m.a.s.l. It comprises thrust slices of Permian to Cretaceous limestone flanked by flysch deposits of Oligocene to Middle Miocene age.

The climate of Cyprus is typical of the eastern Mediterranean (Wilson and Ingham, 1984). From May to October, the climate is relatively warm $\left(18\right.$ to $\left.36^{\circ} \mathrm{C}\right)$ dry and stable while the whole winter period is much cooler $(6$ to $18^{\circ} \mathrm{C}$ ) and rainy. The climate varies across the island in relation to the relief: the annual rainfall is between approximately $1000 \mathrm{~mm}$ (at higher altitudes) and $500 \mathrm{~mm}$ (at lower altitudes) for the Troodos, $350 \mathrm{~mm}$ for the Mesaoria plain and $500 \mathrm{~mm}$ for the Kyrenia range. The predominant runoff into Morphou Bay is from the Troodos owing to the higher rainfall levels, the steeper slopes and the lower
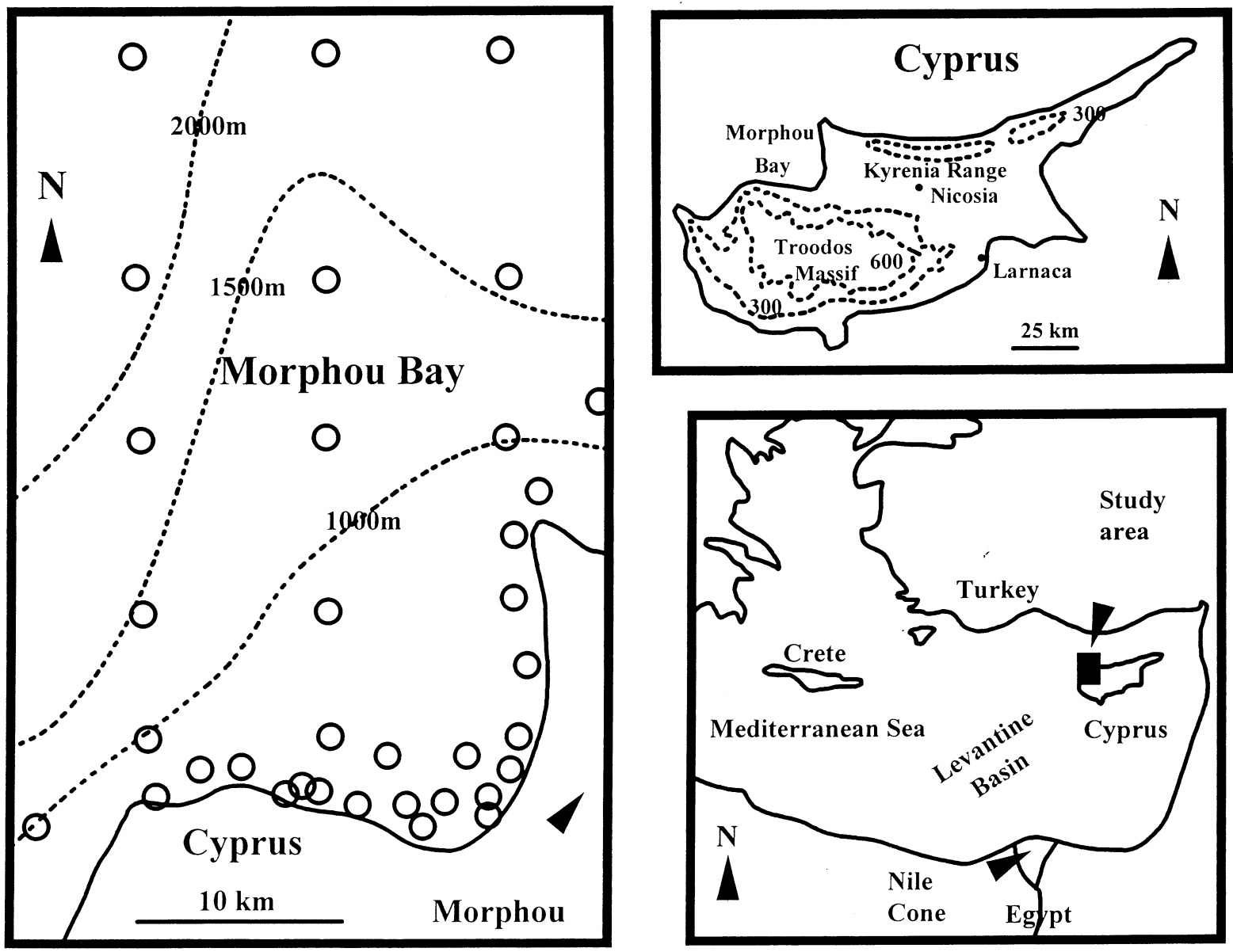

Fig. 1. Location maps for Morphou Bay. The map to the left of the page shows the sample locations (open circles) and water depth (dotted lines), while the maps to the right of the page show Morphou Bay in relation to Cyprus and Cyprus relative to the eastern Mediterranean. 
proportional evaporation and transpiration losses. Runoff from the Troodos enters the southern part of Morphou Bay from streams draining the upper parts of the ophiolite sequence (pillow-lavas/basalts). It also enters the southeastern parts of Morphou Bay from streams that cut across the ophiolite sequence, from the pillow lavas/basalts to the ultrabasic core of the central Troodos Massif (MANR, 1982).

The region is rural with low intensity farming and a low population density particularly within the Troodos.

\section{Sampling and analysis}

32 marine sediments were collected at Morphou Bay by grab sampling during a cruise of the R.V. Shackleton in the autumn of 1972: locations for sampling are indicated in Fig. 1. The samples were air dried and stored for analysis on return to the UK.

In the laboratory, the samples were suspended in distilled water and the less than $20 \mu \mathrm{m}$ fraction was decanted off for subsequent mineralogical and chemical analysis. Initially it was planned that the clay mineral fraction (defined as less than $2 \mu \mathrm{m}$ ) would be studied. However, the material contained a high proportion of highly aggregated smectitic clays that would not disperse sufficiently to effect an efficient separation without the use of strong chemical pre-treatments that would destroy some of the minerals present, contaminate the sample, and rule out meaningful information on matters such as cation exchange capacity and phosphorus and amorphous aluminium and iron oxide content. The $<20 \mu \mathrm{m}$ fraction, nonetheless, is mainly composed of minerals of $<5 \mu \mathrm{m}$ as judged by observations using scanning and transition electron microscopy. The suspensions were then left for an hour or so, until the supernatant liquid looked visibly clear: the settling time was far less than would be appropriate to settle out all but the clay sized fraction $(<2 \mu \mathrm{m})$. The supernatant liquid was then poured off and the remaining sediment was dried at room temperature. The dried material was then stored/archived for later analysis.

Analysis comprised x-ray diffraction (XRD), x-ray fluorescence (XRF) and wet chemical techniques to determine the mineralogy and chemical compositions.

\section{X-RAY DIFFRACTION}

XRD was used to identify the mineral components in the samples and to determine, in part, the proportion of the clay minerals present. Randomly mounted material was scanned to determine the non-clay mineral component of the sediments, with mineral identification being made against reference standard diffractograms. Clay mineral identification was made using samples sedimented onto glass slides to maximise the diffraction peaks used to characterise these components $(\{001\}$ and $\{002\}$ lines). The identification of the clay minerals followed the methodology designed by Carroll (1970). This involved comparisons of the X-ray patterns for sediments treated with (a) ethylene glycol, (b) potassium chloride and (c) heat to 200, 450 and $650^{\circ} \mathrm{C}$. Four main clay minerals were observed. Illite was identified by diffraction maxima at 10,5 and $3.3 \AA$, all of which remain unaffected by glycolation. Smectite was identified by broad diffraction maxima around $14 \AA$ that shifted to a broad peak around 16 to $18 \AA$ on glycolation and to $10 \AA$ on heating to $450^{\circ} \mathrm{C}$. Chlorite was identified by diffraction maxima at 14,7 and $3.5 \AA$ and remained unaffected by glycolation or potassium chloride treatments, although the peaks decreased in intensity on heating to $650^{\circ} \mathrm{C}$. Kaolinite was identified using the major diffraction lines but straightforward identification could not be made using the $\{001\}$ line due to partial masking of the $7 \AA$ basal peak: several other higher order peaks were used for the identification, in most cases, although for some samples, low chlorite levels meant that a clearer identification could be made. The percentage of the clay minerals was determined by comparing the peak areas of the $\{001\}$ diffraction patterns on glycolation. For this, the peak areas were weighted on a basis of 1:2:4 for smectite, illite and chlorite plus kaolinite (Biscay, 1965). Chlorite and kaolinite could not be distinguished because of the closeness of the 7 $\AA$ peak and semi-quantitative separation of these components involved chemical-leaching methodologies described later in the paper. In addition, there were sometimes small and broad peaks in the region of 11 to $13 \AA$ spacing, which 'smeared out' even more on glycolation. These presumably represented mixed-layer clays, but details of the mineralogy could not be assessed due to the small size of the peaks and the presence of other clay mineral peaks.

\section{CHEMICAL DETERMINATIONS}

Chemical determinations comprised four steps. Firstly, bulk chemical compositions were determined by $\mathrm{x}$-ray fluorescence on sediments incorporated into sodium borate diffusion disks. Secondly, the sediments were leached with $10 \%$ hydroxylamine hydrochloride in $20 \%$ concentrated acetic acid to remove carbonate and amorphous/poorlycrystalline iron oxides and hydroxides (about $1 \mathrm{~g}$ of sediment with $100 \mathrm{ml}$ of solution). This approach is based on the method of Chester and Hughes (1967). Thirdly, sediments treated in step two were leached overnight in dilute acid $(2 \% \mathrm{v} / \mathrm{v}$ concentrated hydrochloric acid) which is known 
to dissolve chlorite (Deer et al., 1962; Carroll, 1970). For steps 2 and 3, magnesium and iron concentrations were determined by atomic absorption. Fourthly, cation exchange capacity (cec) was determined by treatment of the sediments with $1 \mathrm{M}$ ammonium acetate to saturate the exchange sites with ammonium ions and the major cations ( $\mathrm{Na}, \mathrm{K}, \mathrm{Mg}$ and Ca) displaced by the leach were determined by atomic absorption spectroscopy. During the leach, some of the calcite dissolved and the amount dissolved was assessed by acidimetric titration that determined the amount of bicarbonate/carbonate generated. The cation exchange capacity was calculated as the sum of the major exchangeable cations minus the bicarbonate/carbonate released. The cec is expressed in units of $\mathrm{mEq} \mathrm{kg}^{-1}$ : individual exchangeable cations could not be determined because of the washing methodologies disrupting the equilibrium.

\section{MINERALOGICAL ASSESSMENT: COMBINED XRD, XRF AND CHEMICAL TECHNIQUES}

The major mineralogical components were determined by a combination of XRD, XRF and chemical techniques as follows.

\section{Calcium carbonate}

The XRD patterns provided strong calcite peaks. The percentage of calcium in the bulk sample was used to determine the percentage of calcite in the samples: calcium is present primarily in the carbonate phase (exchangeable and non carbonate minerals bound calcium is of second order importance). XRD shows small shifts in d-spacing compared to high-purity-calcite diffractograms, while chemical leaching gives magnesium release during carbonate dissolution. These features indicate minor substitution of magnesium within the calcite lattice of about one magnesium ion for every 10 calcium ions. Such a degree of magnesium substitution is common in calcites (Deer et al., 1975). For the remaining part of the study, the percentage of carbonate is referred to as the percentage calcite: for completeness, a small allowance was made for the mass weight linked to the carbonate substitution.

\section{Amorphous iron oxides/hydroxides}

This fraction was determined directly from the hydroxylamine hydrochloride/acetic acid leach described above. The formula weight used to calculate this fraction was taken to correspond to $\mathrm{Fe}_{2} \mathrm{O}_{3}$.

\section{Clay minerals}

The percentage of the clay minerals in each sample was taken as $100 \%$ minus the major non-clay-mineral components (calcite and amorphous iron oxides/ hydroxides). From the diffractograms, the relative proportions of smectite, kaolinite + chlorite (the combined $7 \AA$ peak value) and illite were determined, together with amphibole, and these proportions were scaled to the percentage of the clay minerals in the samples. In the case of chlorite and kaolinite, another step was required to determine the percentages of these clay minerals in the sample. This case is described below.

\section{Kaolinite and chlorite}

As mentioned above, the chlorite and kaolinite percentages could not be calculated directly from the XRD patterns due to the overlap of the $7 \AA$ basal peaks. The chlorite was therefore determined separately using step 3 of the chemical methods described above and the percentage of kaolinite was then determined by the difference between this value and the percentage of $7 \AA$ mineral estimated from diffractometry . $^{\text {. }}$.

For the chlorite determination, linear regression of the step 3 data showed that

$$
\% \mathrm{Mg}=(0.52 \pm 0.12) * \% \mathrm{Fe}-(0.19 \pm 0.32) .
$$

For this relationship, the regression is based on a mg per $\mathrm{mg}$ basis and $\mathrm{r}^{2}=0.712, \mathrm{~N}=32$ and the \pm term in the brackets represent twice the standard error. Thus, the magnesium and the iron show a strong linear feature with an intercept not significantly different from zero. This means that on a molar basis, the $\mathrm{Mg}: \mathrm{Fe}$ ratio is about 1.2. With a unit formula for chlorite of $\left(\mathrm{Mg}^{2+}+\mathrm{Fe}^{2+}\right)_{10}\left(\mathrm{Si}_{6} \mathrm{Al}_{2}\right) \mathrm{O}_{20}(\mathrm{OH})_{16}$ (Newman, 1987), the iron content is about $26 \%$ assuming that the major portion of the iron is in a divalent state: similar results occur if allowance is also made for iron within a mixed divalenttrivalent state. The percentage chlorite was calculated by scaling the percentage iron leached by the step 3 procedure by a factor of $100 / 26$. The iron rich nature of the chlorite

$\S$ The extraction methodology combined with the XRD analysis probably does not provide an accurate estimate of the chlorite and kaolinite content of the sediments. However, there was no means at the time of the study for more exacting methodologies for separation. The separation is maintained for this study because, as can be judged from the results presented within this paper, (a) the mineral percentages fit with other studies for the region, (b) the spatial distributions observed seem reasonable and correspond to what "would be expected" and (c) the results fit with the diffraction information on the type of chlorite actually present in the area and mineral composition of chlorites in the area. 
was confirmed qualitatively by the XRD analysis, which show weak $\{001\}$ and $\{003\}$ but strong $\{002\}$ and $\{004\}$ diffraction maxima (cf. Grim 1968). Furthermore, the gradient of 0.52 corresponds well with greenschist facies chlorite for Cyprus of 0.7 (Hey, 1954) and $\mathrm{Mg}$ and Fe rich chlorites occur as alteration products within areas such as ophiolites with high $\mathrm{Mg}$ and Fe but low Al content (Deer et al., 1962).

\section{Amphibole}

An amphibole was identified using XRD by the presence of a strong $\{110\}$ reflection around $8.5 \AA$. The type of amphibole present could not be determined due to the smallness of the major peaks and lack of smaller reflections above background. For the present study, the proportion of amphibole present in the sediments was assessed semiquantitatively by including the mineral within the x-ray analysis of the "clay mineral fraction": for this purpose, a weighting factor of one was used.

\section{Results}

\section{GENERAL}

The XRD data coupled with the chemical analysis show the presence of four clay minerals, smectite, chlorite, illite and kaolinite. All of these clay minerals are disordered. Thus, they are of relatively low crystallinity as shown by broad peaks of the basal $\{001\}$ reflections: in the case of kaolinite, the low crystallinity is marked by a low Hinckley (1963) index of 0.5 to 0.7 compared to a value of 1.2 for crystalline forms. Other minerals present include calcite with minor magnesium substitution, an amphibole and quartz. Of these, calcite can be a major fraction of the sediment, the amphibole at much lower concentrations (a few percent) and quartz at an even lower concentration. For smectite, there are broad basal reflections that show a range of increases in $\{001\}$ with glycolation and, in part, this reflects a smectite-mixed interlayer clay. In relation to cation exchange capacity, values are relatively high for fine-grained sediments at 230 to $730 \mathrm{mEq} \mathrm{kg}^{-1}$. Such high values are to be expected given the high clay mineral content and the predominance of smectite/mixed-interlayer components: the cec of the major clay minerals is 800 to $1500 \mathrm{mEq} \mathrm{kg}{ }^{-1}$ for smectite/mixedinterlayer clay, 100 to $400 \mathrm{mEq} \mathrm{\textrm {kg } ^ { - 1 }}$ for chlorite and illite, and 30 to $150 \mathrm{mEq} \mathrm{kg}^{-1}$ for kaolinite (Grim, 1968).

The results of this study are summarised in Tables 1 and 2 and in Figs. 2 and 3. Information on averages and ranges in concentration for both mineralogy and chemistry are provided in Table 1. For this table, the data are subdivided into four categories chosen broadly to represent both the whole dataset and the major sources of supply of sediments.

1. The full dataset. This shows the mineralogical and chemical range for the area.

2. The offshore (deep water) sediments. This fraction represents the influence of lithogenous sediment inputs from (a) further afield than Cyprus (i.e. other parts of the eastern Mediterranean) and (b) from Cyprus attenuated by physical sorting of sediments away from the shoreline. This fraction will also contain pelagic inputs.

3. The near-shore sediments to the east of Morphou Bay. This provides information for an area where inputs from the western edge of the Kyrenia range and Mesaoria Plain will be highest together with inputs from the lavas and central ultrabasic core of the Troodos Massif.

4. The near-shore sediments to the south of the Bay. This provides information for an area where inputs from the Troodos is maximal.

Table 2 provides the percentage of the clay minerals normalised to $100 \%$ and details of the relative proportion of the clay minerals in the same four categories as those presented in Table 1. Figures 2 and 3 provide graphical representations of the spatial distribution of the various minerals. In Fig. 2, the spatial variations in the percentages of the various clay minerals, amorphous iron oxides/ hydroxides and the calcite are presented. Figure 3 shows the percentage of the clay minerals normalised to $100 \%$. For Figs. 2 and 3, contour lines of mineral percentages are produced using statistical based contouring (LOWESS smoothing with tension $=0.5$ ) using the statistical package SYSTAT (SPSS, 1996). The results are summarised below.

\section{Mineralogy}

On average, the main mineral present is smectite at around $45 \%$. This is followed by calcite (24\%) and kaolinite (15\%) with chlorite and illite each making up about $5 \%$. However, spatial variations in mineralogy are observed. In detail, the major variations in mineralogy are:

- Smectite. Smectite comprises 21 to $62 \%$ of the Morphou Bay fine-grained sediments. Smectite percentages increase uniformly in a southerly direction from about $30 \%$ offshore to about $54 \%$ in the southern near-shore area and to an intermediate value $(46 \%)$ in the eastern near-shore area.

- Calcite. Calcite makes up 10 to $42 \%$ of the fine-grained sediments. There is a uniform decrease in concentration 
Table 1. A summary of the mineralogy and chemical composition of the fine-grained-Morphou Bay sediments. For the summary, the data is split into (a) the full data record, (b) the offshore (deep water) sediments, (c) the near-shore sediments to the east of the Bay and (d) the near-shore sediments to the south of the Bay. All units are as percentage except for cation exchange capacity $\left(\mathrm{mEq} \mathrm{kg}^{-1}\right)$.

\begin{tabular}{lrrrrrrrrrrrr}
\hline & & \multicolumn{1}{c}{ All } & \multicolumn{4}{c}{ Off shore } & \multicolumn{3}{c}{ Near-shore $W$} & \multicolumn{3}{c}{ Near-shore $S$} \\
& Avg & \multicolumn{1}{c}{ Min } & Max & Avg & \multicolumn{1}{c}{ Min } & Max & Avg & Min & Max & Avg & Min & Max \\
\hline Chlorite & $\mathbf{6 . 4}$ & 3.5 & 9.9 & $\mathbf{5 . 4}$ & 3.6 & 8.3 & $\mathbf{8 . 6}$ & 6.6 & 9.9 & $\mathbf{6 . 2}$ & 3.5 & 8.1 \\
Kaolinite & $\mathbf{1 5 . 4}$ & 6.5 & 29.4 & $\mathbf{1 3 . 4}$ & 6.6 & 21.4 & $\mathbf{1 9 . 5}$ & 9.7 & 29.4 & $\mathbf{1 4 . 9}$ & 6.5 & 20.8 \\
Amphibole & $\mathbf{3 . 2}$ & 0.0 & 10.3 & $\mathbf{1 . 1}$ & 0.0 & 2.6 & $\mathbf{5 . 9}$ & 2.5 & 10.3 & $\mathbf{3 . 6}$ & 0.0 & 6.2 \\
Illite & $\mathbf{5 . 2}$ & 0.0 & 12.9 & $\mathbf{8 . 9}$ & 5.2 & 12.9 & $\mathbf{2 . 8}$ & 0.0 & 7.5 & $\mathbf{3 . 1}$ & 0.0 & 6.3 \\
Smectite & $\mathbf{4 5 . 4}$ & 21.5 & 62.2 & $\mathbf{3 5 . 5}$ & 21.5 & 51.3 & $\mathbf{4 6 . 4}$ & 30.4 & 60.5 & $\mathbf{5 3 . 9}$ & 44.4 & 62.2 \\
Calcite & $\mathbf{2 4 . 4}$ & 9.9 & 41.6 & $\mathbf{3 5 . 6}$ & 26.8 & 41.6 & $\mathbf{1 6 . 8}$ & 14.3 & 21.1 & $\mathbf{1 8 . 2}$ & 9.9 & 32.5 \\
& & & & & & & & & & & & \\
& & & & & & & & & & & & \\
Si & $\mathbf{1 8 . 2 5}$ & 13.39 & 21.65 & $\mathbf{1 5 . 6 4}$ & 13.39 & 17.98 & $\mathbf{2 0 . 3 0}$ & 18.88 & 21.48 & $\mathbf{1 9 . 5 5}$ & 17.58 & 21.65 \\
Ti & $\mathbf{0 . 3 8}$ & 0.30 & 0.46 & $\mathbf{0 . 3 5}$ & 0.32 & 0.39 & $\mathbf{0 . 4 3}$ & 0.33 & 0.46 & $\mathbf{0 . 3 9}$ & 0.30 & 0.44 \\
K & $\mathbf{1 . 0 8}$ & 0.75 & 1.39 & $\mathbf{1 . 2 2}$ & 0.97 & 1.39 & $\mathbf{0 . 9 5}$ & 0.75 & 1.08 & $\mathbf{1 . 0 1}$ & 0.86 & 1.23 \\
Mg & $\mathbf{1 . 3 8}$ & 0.83 & 2.52 & $\mathbf{1 . 1 6}$ & 0.83 & 2.03 & $\mathbf{1 . 7 4}$ & 1.40 & 2.52 & $\mathbf{1 . 3 8}$ & 0.91 & 2.27 \\
Ca & $\mathbf{9 . 0 2}$ & 3.64 & 15.36 & $\mathbf{1 3 . 1 6}$ & 9.88 & 15.36 & $\mathbf{6 . 1 9}$ & 5.28 & 7.80 & $\mathbf{6 . 7 0}$ & 3.64 & 12.00 \\
Sr & $\mathbf{0 . 1 0}$ & 0.02 & 0.18 & $\mathbf{0 . 1 6}$ & 0.11 & 0.18 & $\mathbf{0 . 0 5}$ & 0.04 & 0.09 & $\mathbf{0 . 0 7}$ & 0.02 & 0.14 \\
Al & $\mathbf{6 . 4 1}$ & 5.12 & 7.75 & $\mathbf{5 . 7 1}$ & 5.12 & 6.31 & $\mathbf{7 . 0 2}$ & 6.64 & 7.55 & $\mathbf{6 . 7 2}$ & 5.43 & 7.75 \\
Fe & $\mathbf{3 . 6 7}$ & 2.47 & 5.33 & $\mathbf{2 . 8 0}$ & 2.48 & 3.15 & $\mathbf{4 . 4 1}$ & 3.49 & 5.16 & $\mathbf{4 . 0 7}$ & 2.47 & 5.33 \\
Fe (am) & $\mathbf{0 . 5 3}$ & 0.16 & 2.72 & $\mathbf{0 . 2 2}$ & 0.17 & 0.32 & $\mathbf{1 . 1 5}$ & 0.37 & 2.72 & $\mathbf{0 . 4 8}$ & 0.16 & 0.87 \\
Mn & $\mathbf{0 . 1 1}$ & 0.08 & 0.18 & $\mathbf{0 . 1 1}$ & 0.09 & 0.14 & $\mathbf{0 . 0 9}$ & 0.08 & 0.10 & $\mathbf{0 . 1 1}$ & 0.08 & 0.18 \\
P & $\mathbf{0 . 0 7}$ & 0.05 & 0.11 & $\mathbf{0 . 0 8}$ & 0.07 & 0.11 & $\mathbf{0 . 0 7}$ & 0.06 & 0.09 & $\mathbf{0 . 0 7}$ & 0.05 & 0.09 \\
& & & & & & & & & & & & \\
cec & $\mathbf{4 8 0}$ & 230 & 730 & $\mathbf{3 1 0}$ & 230 & 390 & $\mathbf{5 0 0}$ & 390 & 690 & $\mathbf{6 2 0}$ & 440 & 730 \\
\hline
\end{tabular}

Table 2. A summary of the relative percentages of the clay minerals in fine-grained Morphou Bay sediments. For the summary, the data is split into (a) the full data record, (b) the offshore (deep water) sediments, (c) the near-shore sediments to the east of the Bay and (d) the near-shore sediments to the south of the Bay.

\begin{tabular}{|c|c|c|c|c|c|c|c|c|c|c|c|c|}
\hline & & All & & & Offsh & & & Near & ore $W$ & & Near & hore $S$ \\
\hline & $A v g$ & Min & $\operatorname{Max}$ & $A v g$ & Min & $\operatorname{Max}$ & $A v g$ & Min & $\operatorname{Max}$ & $A v g$ & Min & $\operatorname{Max}$ \\
\hline Chlorite & 8.8 & 5.3 & 12.6 & 7.9 & 6.2 & 10.9 & 10.9 & 5.4 & 12.6 & 8.1 & 5.3 & 10.3 \\
\hline Kaolinite & 21.4 & 8.7 & 38.5 & 23.1 & 9.1 & 37.0 & 22.0 & 9.5 & 38.5 & 20.0 & 8.7 & 32.8 \\
\hline Illite & 7.8 & 0.0 & 21.6 & 15.1 & 8.3 & 21.6 & 5.9 & 0.0 & 13.3 & 4.3 & 0.0 & 10.3 \\
\hline Smectite & 62.0 & 37.1 & 81.1 & 53.9 & 37.1 & 70.8 & 61.3 & 39.8 & 75.5 & 67.6 & 58.2 & 81.1 \\
\hline
\end{tabular}

in a southerly direction from about $40 \%$ offshore to about $17 \%$ in the eastern and southern near-shore areas.

- Kaolinite. Kaolinite makes up 6 to $30 \%$ of the finegrained sediment. The highest percentages occur offshore to the north and near-shore to the east (typically 15 to $20 \%$ ) with the lowest values typically occurring in the mid-Bay area.
- Chlorite. Chlorite comprises 3 to $10 \%$ of the finegrained sediments. There is a gradient of increase in the percentage of chlorite from about $4 \%$ offshore to the northwest to about $9 \%$ by the eastern near-shore.

- Illite. Illite varies between 0 and $13 \%$ in the fine-grained sediments. There is a uniform decrease in content from the offshore to the north (about 10\%) to the near-shore 

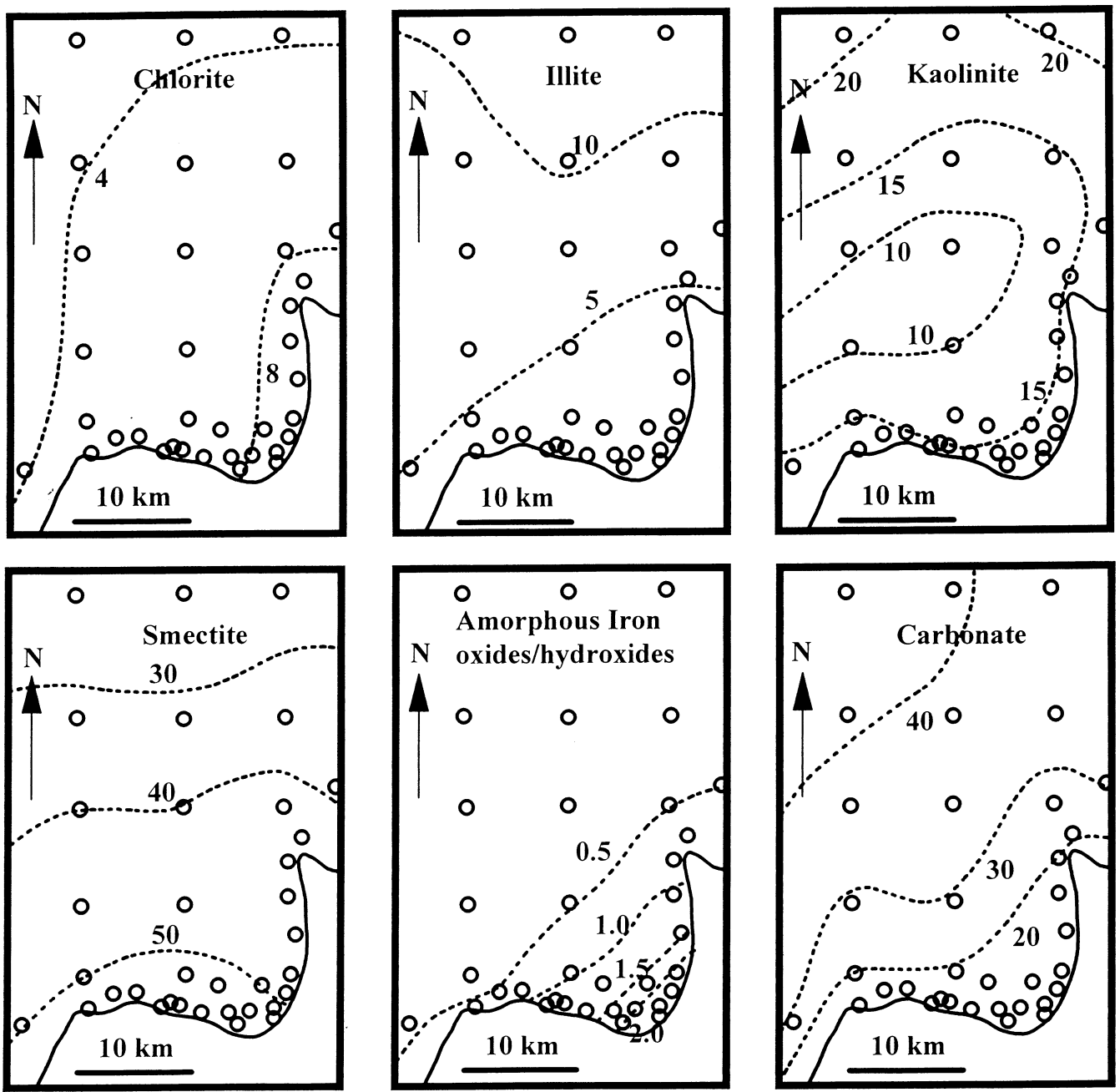

Fig. 2. The distribution of chlorite, illite, kaolinite, smectite, amorphous iron oxides/hydroxides and carbonate (calcite) in Morphou Bay fine-grained sediments

in the south and east (about 3\%).

- Amphibole. This is present at between 0 and $10 \%$ in the fine-grained sediments. The highest levels occur in the near-shore fine-grained sediments: $6 \%$ and $4 \%$ in the western and southern near-shore areas, respectively and about $1 \%$ offshore.

- Amorphous iron oxides/hydroxides. 0.2 to $2.7 \%$ of the fine-grained sediments comprise amorphous iron oxides/hydroxides phases. The highest concentrations occur near-shore, more so to the west than the south (1.2 and $0.5 \%$, respectively), while lower concentrations of about $0.2 \%$ occur offshore.

\section{Chemistry}

The chemistry of the fine-grained sediments is relatively uniform. The sediments are $\mathrm{Si}, \mathrm{Ca}, \mathrm{Al}, \mathrm{Fe}$ and $\mathrm{K}$ bearing (typically 18, 9, 6, 4 and 1\%, respectively) and they contain significant but lower levels of Ti, $\mathrm{Mn}, \mathrm{Sr}$ and $\mathrm{P}(0.38,0.11$, 0.10 and $0.07 \%$, respectively). Nonetheless, there are some important spatial patterns, which correspond primarily with near-shore to offshore variations. Three groupings are observed.

1. K, Ca and Sr. For these elements, the percentages present in the fine-grained sediments decrease from offshore to near-shore. In the case of potassium, the decrease is relatively small (1.2 to 1.0$)$. However, for $\mathrm{Ca}$ and $\mathrm{Sr}$ the decrease is about a factor of two (13.2 to 6.5 and 0.16 to $0.06 \%$, respectively).

2. Si, Ti, Mg, Al and Fe. For these elements, the percentages present in the fine-grained sediments increase moderately from offshore to near-shore (16 to $20,0.35$ to $0.42,1.2$ to $1.5,5.7$ to 6.9 and 2.8 to $4.2 \%$, respectively).

3. Mn and $\mathbf{P}$. These elements show no clear spatial variability. 

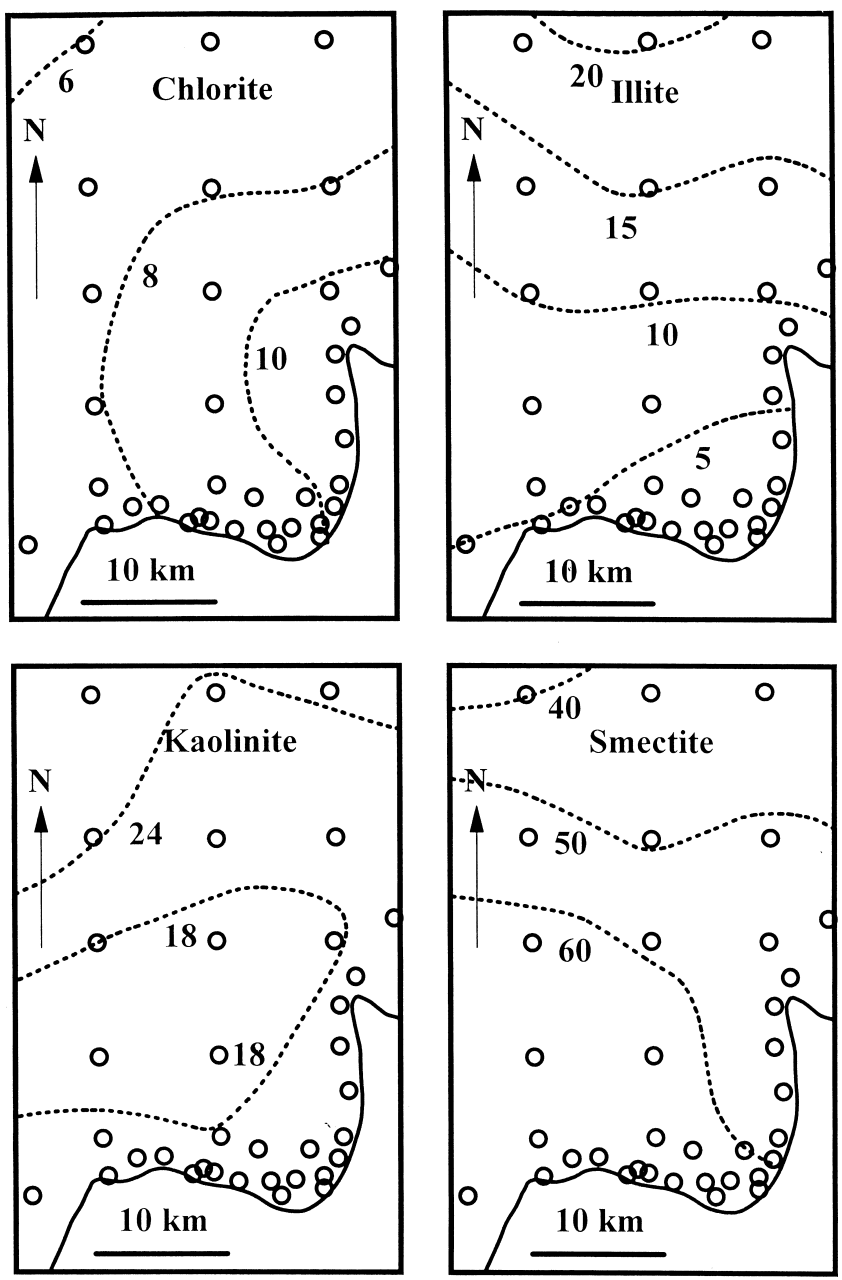

Fig. 3. The aerial variations in the relative proportions of the clay minerals (chlorite, illite, kaolinite and smectite) in the fine-grained sediments of Morphou Bay

\section{STATISTICAL ANALYSIS}

To explore the detailed relationships between the mineralogy and chemistry coupled to their linkages with spatial variations across Morphou Bay, statistical analysis was undertaken using correlation matrices, multiple linear regression and principal component methods using the SYSTAT package (SPSS, 1996). The results are as follows.

\section{Correlation matrices}

The mineralogical and chemical data show a high degree of correlation structure that broadly reflects the patterns of behaviour described earlier in the paper. The main features observed are:

1. Illite, calcite, $\mathrm{Ca}, \mathrm{K}, \mathrm{Sr}$, latitude and depth: group 1 . These show high positive inter-correlations $\left(\mathrm{R}^{2}\right.$ typically greater than $0.7, \mathrm{~N}=32$ ).
2. Chlorite, amphibole, smectite, \%clay, $\mathrm{Si}, \mathrm{Ti}, \mathrm{Al}, \mathrm{Fe}$, Fe(amorphous), Mg and cec: group 2. These show high positive inter-correlations $\left(\mathrm{R}^{2}\right.$ typically greater than $0.7, \mathrm{~N}=32$ ).

3. Group 1 and the group 2 components. These two groups show high negative inter-correlations $\left(\mathrm{R}^{2}\right.$ typically greater than $0.7, \mathrm{~N}=32$ ).

4. Kaolinite and $\mathbf{P}$. There are no clear correlations $\left(\mathrm{R}^{2}\right.$ typically less than $0.2, \mathrm{~N}=32$ ).

\section{Multiple linear regression analysis}

To compare the mineralogy and chemistry in such a way that each chemical determinand is related to individual minerals, multiple linear regression analysis was undertaken for the total sediments. For this, each chemical determinand was regressed against chlorite, kaolinite, amphibole, illite, smectite, calcite and amorphous iron oxides/hydroxides. The results of this exercise indicate relatively weak correlations in most cases: for $\mathrm{Si}$ and $\mathrm{P}$, no statistically significant correlation was found with any of the mineral phases. The statistically significant correlations observed were as follows.

- $\mathbf{T i}$ is positively correlated with chlorite $(\mathrm{p}=0.030)$.

- Al is negatively correlated with calcite $(\mathrm{p}=0.000)$.

- Fe is positively correlated with amorphous iron oxides/ hydroxides $(\mathrm{p}=0.001)$ and negatively correlated with chlorite $(\mathrm{p}=0.001)$ and calcite $(\mathrm{p}=0.000)$.

- $\quad M n$ is positively correlated with calcite $(\mathrm{p}=0.046)$.

- Mg is positively correlated with amorphous iron oxides/ hydroxides $(\mathrm{p}=0.013)$.

- $\mathbf{K}$ is positively correlated with illite $(\mathrm{p}=0.026)$ and calcite $(\mathrm{p}=0.011)$.

- $\quad$ cec is negatively correlated with calcite.

- $\mathrm{Sr}$ is positively correlated with calcite $(\mathrm{p}=0.000)$.

\section{Principal component analysis}

Principal component analysis reveals that there is only one major component loading and this comprises the group 1 components in negative relationship with the group 2 determinands identified within the correlation analysis described earlier in the paper. $59 \%$ of the variance is explained by this first principal component. A further $10 \%$ of the variance is explained by a second principal component, latitude; an additional $7 \%$ of the variance is explained by a third principal component $(\mathrm{P}$ and $\mathrm{Mg}$ in a negative relationship with kaolinite). 


\section{Discussion}

\section{GENERAL}

The chemical and mineralogical composition of fine-grained sediments in Morphou Bay show relatively uniform chemistries with some spatial variations linked to local sources from north-eastern Cyprus (the Troodos in particular) and from further afield in the eastern Mediterranean. There are three main features to note, one with respect to the clay minerals in the sediments, a second linked to the mineral assemblage as a whole and a third which describes the system in terms of endmember mixing relationships. These three features are outlined below.

\section{The clay minerals}

Offshore Morphou Bay, the clay minerals present in the finegrained sediments are very similar to those reported by Venkatarathnam and Ryan (1971) for the eastern Mediterranean, with smectite predominating ( 55\%) followed by kaolinite $(\sim 20 \%)$, illite $(\sim 15 \%)$ and chlorite $(\sim 7 \%)$. Near-shore at Morphou Bay, the relative proportions of the clay minerals change, with a greater proportion of smectite $(\sim 65 \%)$, kaolinite and chlorite remaining at approximately the same value ( $\sim 21$ and $\sim 8 \%$ respectively) and a lower proportion of illite $(\sim 5 \%)$. The clay mineral variation broadly reflects a mixing of two clay mineral assemblages, one from the eastern Mediterranean and the other from Cyprus. However, in detail, there may be a minor subdivision of the Cyprus inputs from the south and east of Morphou with a higher proportion of smectite in the south and perhaps a slightly higher proportion of chlorite and kaolinite to the east.

The chemical composition of the clay minerals cannot be assessed generally due to the presence of clay mineral mixtures in the fine-grained sediments and the relatively small variability in composition. There are two exceptions where partial compositions can be gauged.

Firstly, for chlorite, a chemical leach, backed up by XRD analysis, reveals that the chlorite is iron rich.

Secondly, for illite there is a strong correlation with potassium. This is to be expected, as potassium is a major component within illite. Linear regression analysis reveals

$$
\mathrm{K} \%=(0.041 \pm 0.0012) * \% \text { illite }+(0.77 \pm 0.22)
$$

$$
\mathrm{r}^{2}=0.678, \mathrm{~N}=32
$$

There are two main features to this relationship. Firstly, the gradient of this line indicates that the $\mathrm{K}$ content of the illite is about $4 \%$. This value is consistent with values for poorly crystalline illite (Newman, 1987) and with the broad diffraction patterns observed that indicate low crystallinity. Secondly, the intercept of this line is non-zero and clearly some other phase or phases in the sediment are $\mathrm{K}$ bearing. It is not clear what this additional phase is, but as the smectite phase includes a component of mixed interlayering, potassium could easily be associated with illitic units and other clay mineral units possessing trivalent ions substituted for silicon within the tetrahedral layers.

\section{The mineral assemblage}

Considering the mineralogy and chemistry of the finegrained sediments as a whole, superimposed on the patterns of clay mineral distribution is the variation of the other components present in the fine-grained sediments and their diluting influence on the clay minerals. There are two types of component to consider, lithogenous and pelagic materials:

- The lithogenous components in the fine-grained Morphou Bay sediments are the clay minerals, an amphibole and amorphous iron oxides/hydroxides. Of these components, the clay mineral distribution is

Table 3. A comparison of the relative percentages of clay minerals in fine-grained sediments of (a) the Eastern Mediterranean, (b) offshore Morphou Bay and (c) near-shore Morphou Bay. The table provides a range of values for the eastern Mediterranean to cover the wide aerial distribution, while averages are provided for the more localised Morphou Bay area. For the near-shore Morphou Bay data, two values are presented in the table, the southern near-shore and, bracketed, eastern near-shore.

\begin{tabular}{lllll}
\hline & Smectite & Kaolinite & Chlorite & Illite \\
\hline Eastern Mediterranean & $50-60$ & $15-20$ & $5-7$ & $10-20$ \\
Morphou Bay off shore & 54 & 23 & 8 & 15 \\
Morphou Bay near-shore & $68(61)$ & $20(22)$ & $9(11)$ & $4(6)$ \\
\hline
\end{tabular}


essentially described earlier in the paper (but with increasing dilution from calcite away from shore). For the amphibole and amorphous iron oxides/hydroxides, their concentrations are highest near-shore due to localised inputs from Cyprus. However, there may be a complicating factor of mobilisation of iron by reduction deeper in the sediments to precipitate at the sediment surface in more oxic conditions (Burton and Liss, 1976). In detail, there may be a higher input of the amphibole and amorphous iron oxides/hydroxides from the east of the bay. Regarding the source of the amphibole and amorphous iron oxides/hydroxides, four features explain the patterns observed. Firstly, rainfall, overall, is low and evaporation high to the north-eastern parts of Cyprus draining into Morphou Bay. Secondly, the southern and south-eastern parts of Morphou Bay have riverine inputs from the Troodos that have much higher rainfall. Thirdly, the south-eastern part of Morphou Bay has sediment inputs from rivers draining the basic and ultrabasic areas of the Troodos, which receive relatively high rainfall inputs (MANR, 1982). Fourthly, it is in the ultrabasic areas where the amphibole tremolite is particularly prevalent and it occurs in a microcrystalline form (Wilson and Ingham, 1984); this, on erosion, would enter into the fine fraction of the resultant sediments. Therefore, it seems that the south-eastern part of Morphou Bay may be enriched in at least one mineral (amphibole) from the more ultrabasic areas of the Troodos. Inputs of fine-grained materials to Morphou Bay from the east and to the north of the ophiolites will probably be quartz and iron oxide bearing (Moore, 1960). Despite the qualification for amorphous iron oxides/hydroxides, and potential variations in Cyprus based sediment sources, the variations in the lithogenous components can be viewed largely as the clay minerals: i.e. in terms of the mixing of eastern Mediterranean and Cyprus derived materials. Within the lithogenous component, there may also be some calcite from riverine suspended sediment draining into Morphou Bay from the western limit of the Kyrenia range, Morphou Plain and the lower slopes and coastal plain of north/north-east Troodos.

- There is a pelagic input of calcite. This pelagic input dilutes the lithogenous phases. The calcite increases in the fine-grained sediments off shore to the north of the study area. However, since part of the calcite component may be associated with lithogenous sources as well and the relative partitioning between lithogenous and pelagic sources cannot be assessed here.

\section{Endmember mixing}

The variations in the chemical compositions of the finegrained sediment at Morphou Bay reflect the mixing of the lithogenous components (the clay minerals, amphibole and amorphous iron oxide/hydroxides possibly including some calcite) and the pelagic component (calcite). As the proportion of the calcite increases then the proportions of the lithogenous materials decline and this results in a lowering of the elements that make up these minerals ( $\mathrm{Si}$, $\mathrm{Ti}, \mathrm{Al}, \mathrm{Mg}$ and $\mathrm{Fe}$ ). In contrast, there are positive relationships between calcite, $\mathrm{Sr}$ and $\mathrm{K}$. In the case of strontium, this element substitutes for calcium in the calcite lattice which is why there is a strong linear relationship between strontium and calcium and why there is an intercept that does not differ significantly from zero

$$
\begin{aligned}
& \mathrm{Sr} \%=(0.0140 \pm 0.0014) * \mathrm{Ca} \%-(0.025 \pm 0.033) \\
& \mathrm{r}^{2}=0.918, \mathrm{~N}=32 .
\end{aligned}
$$

This corresponds to substitution of one atom of $\mathrm{Sr}$ for every 156 atoms of $\mathrm{Ca}$. Such a level of substitution is commonly found in calcite (Deer et al., 1975). However, for potassium, this element will be associated with the clay minerals, illite in particular, rather than in the calcite lattice. Thus, the linear feature between calcite and potassium is probably indirect; both calcite inputs and eastern Mediterranean lithogenous inputs increase northwards away from the Morphou Bay shoreline. The calcite distribution pattern resembles the mixing of lithogenous assemblages derived from the eastern Mediterranean and Cyprus.

The overall pattern of mineralogical and chemical variability can, thus, be represented broadly in terms of twocomponent mixing of mineral assemblages from the eastern Mediterranean and Cyprus. However, in detail, there is a three component mix (1) lithogenous illitic bearing clay minerals from the eastern Mediterranean, (2) pelagic inputs of calcite from the eastern Mediterranean and (3) lithogenous clays rich in smectite and containing amphibole and amorphous iron oxides/hydroxides from the Troodos of Cyprus.

\section{TYPOLOGY}

The typology of the fine-grained marine sediments supplied from the ophiolite area of the Troodos is represented by a high proportion of smectite/mixed interlayer clays. The sediments, excluding the calcite component, are $\mathrm{Si}, \mathrm{Al}, \mathrm{Fe}$ and $\mathrm{Mg}$ bearing and this reflects the dominance of these elements within the ophiolite sequence (Table 4). 
Table 4. A comparison of the chemical composition of fine-grained sediments to the south of Morphou Bay (material transported from the Troodos) igneous rocks from the Troodos. In the table, the percentage chemical compositions are presented together with the ratios to silicon and for the Morphou Bay sediments the percentages are on a calcite free basis. The rocks referred to comprise two of the main units of the Troodos ophiolite: (1) basic lavas (basalt) of the lower Troodos (the upper, crustal, part of the ophiolite sequence) and (2) ultrabasic rocks (diopsidic peridotite and dunite) from the upper elevations of the Troodos Massif (the lower, upper-mantle, part of the ophiolite sequence). The chemical data for the rocks of Troodos is taken from Wilson and Ingram (1984).

\begin{tabular}{lllll}
\hline & $\begin{array}{l}\text { Morphou Bay } \\
\text { Near-shore south } \\
\%\end{array}$ & $\begin{array}{l}\text { Troodos } \\
\text { Basalt } \\
\%\end{array}$ & $\begin{array}{l}\text { Troodos } \\
\text { Peridotite } \\
\%\end{array}$ & $\begin{array}{l}\text { Troodos } \\
\text { Dunite } \\
\%\end{array}$ \\
\hline $\mathrm{Si}$ & 23.9 & 23.6 & 21.6 & 15.7 \\
$\mathrm{Ti}$ & 0.48 & 0.61 & 0.04 & 0.02 \\
$\mathrm{~K}$ & 1.24 & 0.30 & 0.06 & 0.08 \\
$\mathrm{Mg}$ & 1.69 & 1.33 & 17.6 & 25.2 \\
$\mathrm{Ca}$ & - & 8.01 & 8.66 & 0.11 \\
$\mathrm{Al}$ & 8.22 & 8.26 & 1.22 & 0.27 \\
$\mathrm{Fe}$ & 5.00 & 7.78 & 4.84 & 5.34 \\
$\mathrm{Mn}$ & 0.13 & 0.27 & 0.10 & 0.09 \\
$\mathrm{P}$ & 0.09 & 0.05 & 0.06 & 0.02 \\
& & & & Ratio to $\mathrm{Si}$ \\
& Ratio to $\mathrm{Si}$ & Ratio to $\mathrm{Si}$ & Ratio to $\mathrm{Si}$ & \\
$\mathrm{Si}$ & 1 & & & 1 \\
$\mathrm{Ti}$ & 0.020 & 1 & 1 & 0.001 \\
$\mathrm{~K}$ & 0.052 & 0.026 & 0.002 & 0.005 \\
$\mathrm{Mg}$ & 0.071 & 0.013 & 0.003 & 0.600 \\
$\mathrm{Ca}$ & 0.343 & 0.056 & 0.817 & 0.017 \\
$\mathrm{Al}$ & 0.344 & 0.339 & 0.401 & 0.339 \\
$\mathrm{Fe}$ & 0.208 & 0.350 & 0.057 & 0.005 \\
$\mathrm{Mn}$ & 0.006 & 0.329 & 0.224 & \\
$\mathrm{P}$ & 0.004 & 0.012 & 0.005 & 0.003 \\
\hline
\end{tabular}

Table 4 compares the chemical compositions for finegrained sediments to the south of Morphou Bay (material transported from the Troodos) and two of the major rock types which make up the ophiolites of the Troodos. There are several points to note with this table before the salient points can be given:

- The percentage chemical compositions presented together with data normalised to silicon, is used to indicate the relative changes in the particulate loading, as silicon will be retained primarily in the solid phase owing to its low solubility.

- For Morphou Bay sediments, the percentages are presented on a calcite free basis to exclude the pelagic component in the sediment (assuming that the lithogenous calcite component is negligible): the data normalisation to silicon is not affected by this.

- The rocks described comprise two of the main units of the Troodos ophiolite: (1) basalt from the lower Troodos and (2) ultrabasic rocks (diopsidic-peridotite and dunite) from the upper Troodos.

Within the upper parts of the ophiolite, the rocks comprised mainly aluminium and iron rich silicates while the lower parts are magnesium and iron bearing silicates. The weathering products as observed within Morphou Bay reflect these two provenances. However, there is some differentiation between the elements. 
- Si. Silicon levels in the Morphou Bay sediment and the rocks from the Troodos are similar, with the highest values occurring for the sediment. Silicon will be retained largely within the solid phase as the primary rock weathers: it is present as low solubility phases such as quartz and clay minerals.

- Ti. Titanium levels in the Morphou Bay sediment are intermediate between the basic and ultrabasic compositions both in terms of element percentage and normalisation to silicon. However, the titanium levels are much closer to those of the basic than the ultrabasic rocks. Titanium will be retained within the solid phase due to the low solubility of $\mathrm{TiO}_{2}$ and its incorporation into clay minerals. The intermediate composition simply reflects the relative proportions of weathered material from these two sources (possibly augmented by other rock sources). It therefore seems that about three quarters of the Morphou sediment comes from the basalts; perhaps $90 \%$ of the area of Troodos draining into Morphou Bay is derived from the basic lavas while higher erosion rates might be expected for the ultrabasic areas of greater altitude, steeper gradients and higher rainfall.

- K. Potassium shows a three fold or greater enrichment within the Morphou Bay sediments compared to the basic/ultrabasic rocks in terms of percentage and ratio to silicon. Potassium is strongly sorbed onto clay minerals and sorption is higher in sea-water than in freshwater for two reasons. Firstly, potassium concentrations in the sea are orders of magnitude higher than in freshwater and are much more strongly sorbed than the other major cations in sea-water: hence potassium uptake is enhanced in sea-water. Secondly, diagenesis of the clay minerals in the marine sediments can fix the potassium in the clay minerals (Burton and Liss, 1976; Stumm and Morgan, 1996). Thus, enrichment in the marine sediments of Morphou Bay is to be expected.

- Mg. Magnesium shows a similar feature to titanium although the magnesium content of Morphou Bay sediment is very low compared to the ultrabasic rock in terms of percentage and normalisation to silicon. Magnesium will, in part, be retained within the clay weathering products (smectite/mixed layer clays, chlorite and illite, in particular). However, in the ultrabasic areas, surface runoff is of a magnesium bicarbonate type (Neal and Shand, 2002) and part of the magnesium flux from these areas will be in solution. A lower magnesium content in the sediments compared to the ultrabasic rocks might therefore be expected.
- Al. Aluminium also shows a similar feature to titanium. Aluminium, like titanium and silicon, will be retained within the solid phase during weathering due to its incorporation into clay minerals and the formation of aluminium hydroxide precipitates. Aluminium solubility is particularly low in the neutral to moderately alkaline waters draining the ophiolites (Neal and Shand, 2002).

- Fe and Mn. Iron and manganese percentages and ratios to silicon are relatively invariant in the Morphou Bay sediments and the basic/ultrabasic rocks. Iron and manganese will be retained within the sediments due to their low solubility in the neutral to moderately alkaline waters mainly encountered in the ophiolite areas due to the formation of low solubility oxide/hydroxide phases and, for iron, incorporation into clay minerals (chlorite, smectite/mixed interlayer clays and illite in particular).

- P. Phosphorus remains relatively constant in the sediments and the basic/ultrabasic rocks. However, there may be moderate enrichment within the sediments. Phosphorus is retained within weathering products as iron phosphates, calcium phosphates, as co-precipitates with calcite and other dibasic carbonates, and sorbed onto clay, aluminium/iron oxide/hydroxide and organic surfaces.

In terms of typology and coastal zone research, an important aspect is the description of the nutrient functioning since this is of primary concern to links with the ecology of the system. The results presented here show that the Morphou Bay sediments contain about $0.07 \%$ phosphorus and the variation across all the sediments is relatively small (range 0.05 to $0.11 \%$ ). Further, there does not seem to be any significant fractionation of phosphorus between the clay minerals and calcite, as statistical analysis does not reveal any significant patterns. Thus, it seems that for the Cyprus ophiolite system, the background levels within the sediments can be assumed to be relatively constant at around $0.07 \%$, a value slightly higher than the rocks from which they derive. This value is a typical 'background level' for a wide range of igneous (ultrabasic to acidic forms), metamorphic and sedimentary rocks where concentrations lie in the range 0.02 to $0.16 \%$ (cf. Rösler and Lange, 1972). However, this value is low when compared to riverine sediments associated with agricultural and urban river systems. For example, for eastern UK rivers draining a range of rural, agricultural and industrial catchments, suspended sediments average $1.23 \%$ with a range of 0.003 to $24 \%$ and a median value of $0.85 \%$ (data from Neal and Robson, 2000). 


\section{Conclusion}

The study highlights the typology of coastal zone sediments associated with weathering and erosion of ophiolites in an area of high scientific importance. The work shows the dominance of smectite/mixed interlayer clay minerals with additional inputs of amorphous iron oxides/hydroxides and amphibole. Variations in the mineralogy of the sediments are associated with an endmember system linked with lithogenous material from Cyprus and other parts of the eastern Mediterranean and with pelagic inputs of calcite. The chemical variability within the fine-grained sediments reflects the mineralogical changes.

\section{References}

Biscay, P.E., 1965. Mineralogy and sedimentation of recent deepsea clay in the Atlantic Ocean and adjacent seas and oceans. Geol. Soc. Amer. Bull., 76, 803-832.

Burton, J.D. and Liss, P.S., 1976. Estuarine Chemistry. Acad. Press (London), 229pp.

Carroll, D., 1970. Clay minerals: a guide to their x-ray identification. Geol. Soc. Amer., special paper 126, 7-67.

Chester, R. and Hughes, M.J., 1967. A chemical technique for the separation of ferro-manganese minerals, carbonate minerals and adsorbed trace elements from pelagic sediments. Chem. Geol., 3, 199-212.

Crossland, C.J., Kremer, H. and Marshall, J.I. (Eds.), 1999. Regimes of Coastal Change. 4th Open Science Meeting, LOICZ, Bahia Blanca, Argentina, 15-18 November, 1999. LOICZ International Project Office, Netherlands Institute of Sea Research, (NIOZ), P.O. Box 59, 1790-AB Den Burg, Texel, The Netherlands, 146pp.

Deer, W.A., Howie, R.A. and Zussman, J., 1962. The Rock Forming Minerals: Volume 3, Sheet silicates. Longman, Thetford, UK, 270pp.

Deer, W.A., Howie, R.A. and Zussman, J., 1978. The Rock Forming Minerals: Volume 5, Non Silicates. Longman, Thetford, UK, 370pp.

Drever, J.I., 1997. The Geochemistry of Natural Waters: Surface and Groundwater Environments. Prentice-Hall, Upper Saddle River, NJ, USA, 436pp.

Gass, I.G., 1982. Ophiolites. Sci. Amer., 247, 122-131.
Gass, I.G. and Masson-Smith, D., 1963. The geology and gravity anomalies of the Troodos Massif, Cyprus. Phil. Trans. Roy. Soc. London. A. No. 1060, 255, 417-467.

Grim, R.E., 1968. Clay Mineralogy ( $2^{\text {nd }}$ edit.). MacGraw-Hill, New York, USA, 596pp.

Hey, M.H., 1954. A review of the chlorites. Min. Mag., 30, 277292.

Hinckley, D.N., 1963. Variability in "crystallinity" values among the kaolin deposits of the Coastal Plain of Georgia and South Carolina. In: Clays and Clay Minerals, E. Ingerson (Ed.) Pergamon Press (New York), 229-235.

IGBP, 1994. IGBP in action: Workplan 1994-1998. International Geosphere Biosphere Programme, Report No. 25, Stockholm, $151 \mathrm{pp}$.

Leeks, G.J.L. and Jarvie, H.P., 1998. Introduction to the Land Ocean Interaction Study (LOIS): rationale and international context. Sci. Total Envir., 210/211, 5-20.

Lippard, S.J., Shelton, A.W. and Gass, I.G., 1986. The ophiolite of Northern Oman. Memoir 11, Geological Soc. London. Blackwell, Oxford, UK, 178pp.

MANR, 1982. Geological map of Cyprus. Ministry of Agriculture and Natural Resources, Geological Survey Department, Nicosia, Cyprus.

Moore, T.A., 1960. The geology and mineral resources of the Astroeritis-Komakiti area. Mem. Geol. Surv. Dept. Cyprus, 6, $1-90$.

Neal, C. and Robson, A.J., 2000. A summary of river water quality data collected within the Land Ocean Interaction Study: core data for eastern UK rivers draining to the North Sea. Sci. Total. Envir., 251/252, 585-666.

Neal, C. and Shand, P., 2002. Spring and surface water quality of the Cyprus ophiolites. Hydrol. Earth Syst. Sci., 6, 797-817.

Newman, A.C.D., (Ed.), 1987. Chemistry of Clay Minerals. Mineralogical Society Monograph no 6. Longman, Harlow, UK, 480pp.

Rösler, H.J. and Lange, H., 1972. Geochemical Tables. Elsevier, Amsterdam, The Netherlands, 468pp.

SPSS, 1996. SYSTAT 6.0 for Windows. SPSS Inc., 444, North Michigan Ave., Chicago, IL 60611, USA. 5 vols.

Stumm, W. and Morgan, J.J., 1996. Aquatic Chemistry (3 ${ }^{\text {rd }}$ edit.). Wiley, New York, USA, 1022pp.

Venkatarathnam, K. and Ryan, W.B.F., 1971. Dispersal patterns of clay minerals in the sediments of the E. Mediterranean Sea. Mar. Geol., 11, 261-282.

Wilson, R.A.M. and Ingham, F.T., 1984. The geology of the XerosTroodos area. Ministry of Agriculture and Natural Resources, Geological Survey Department, Cyprus. Memoir No. 1, 184pp. 